\title{
EVALUACIÓN EN CONDICIONES DE CAMPO DE UNA PRUEBA SEROLÓGICA RÁPIDA PARA DETECCIÓN DE ANTICUERPOS IGM E IGG CONTRA SARS-COV-2
}

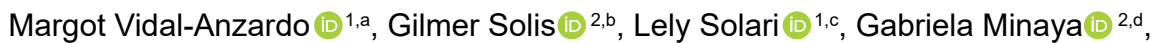

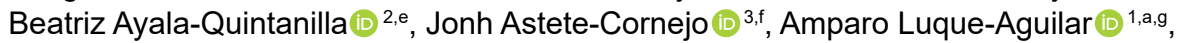 \\ Ana Jorge $\mathbb{1}^{4,9}$, Nancy Rojas $\mathbb{1}^{5,9}$, Fanny Cardenas $\mathbb{1}^{4,9}$, Alonso Soto $\mathbb{1}^{6,7, h}$ \\ 1 Centro Nacional de Salud Pública, Instituto Nacional de Salud, Lima, Perú. \\ 2 Oficina General de Investigación y Transferencia Tecnológica, Instituto Nacional de Salud, Lima, Perú. \\ Centro Nacional de Salud Ocupacional y Protección del Ambiente para la Salud, Lima, Perú. \\ ${ }^{4}$ Laboratorio de Referencia Nacional de Bacterias de Transmisión Sexual, Instituto Nacional de Salud, Lima, Perú. \\ 5 Laboratorio de Referencia Nacional de Virus Respiratorio, Instituto Nacional de Salud, Lima, Perú. \\ 6 Instituto de Investigación en Ciencias Biomédicas, Facultad de Medicina Humana. Universidad Ricardo Palma, Lima, Perú. \\ Departamento de Medicina, Hospital Nacional Hipólito Unanue, Lima, Perú. \\ Médico cirujano; ${ }^{\mathrm{b}}$ Cirujano dentista; ${ }^{\mathrm{c}}$ Médico Infectólogo, doctora en Ciencias de Salud; ${ }^{\mathrm{d}}$ Médico Infectólogo, magíster en \\ Salud Pública y Bioética; ${ }^{\mathrm{e}}$ Médico Ginecobstetra, doctora en Medicina; ${ }^{\mathrm{f}}$ Médico especialista en Medicina Ocupacional y del \\ Medio Ambiente, magíster en Administración de Empresas con especialidad en Gestión Integrada de la Calidad, Seguridad y \\ Medio Ambiente, ${ }^{\mathrm{g}}$ Bióloga, ${ }^{\mathrm{h}}$ Médico especialista en Medicina Interna y Doctor en Ciencias Médicas.
}

\section{RESUMEN}

Objetivos: Determinar el rendimiento diagnóstico adicional de una prueba serológica rápida que detecta anticuerpos IgM e IgG contra SARS-CoV-2 en relación a la reacción en cadena de polimerasa reversa en tiempo real (RT-PCR). Materiales y métodos: Se realizó un estudio transversal incluyendo pacientes hospitalizados por COVID-19 en tres hospitales, trabajadores de salud expuestos a la infección y pacientes ambulatorios que cumplían criterios de caso sospechoso, a quienes se les realizó la prueba molecular (RT-PCR) y la prueba serológica rápida. Se evaluó el rendimiento diagnóstico adicional de las prueba serológica rápida en relación a la molecular. Asimismo, se realizó la estimación de sensibilidad y especificidad de dichas pruebas. Resultados: Se incluyeron 144 personas. La prueba serológica rápida obtuvo un 19,4\% de resultados positivos en comparación con un $11,1 \%$ en la prueba molecular $(\mathrm{p}=0,03)$. La prueba serológica rápida detectó 21 casos que habían resultado negativos por el RT-PCR inicial y el rendimiento diagnóstico adicional fue de 56,8\% en comparación al RT-PCR. El rendimiento diagnóstico adicional fue 50,0\% durante la primera semana, 70,0\% durante la segunda y 50,0\% durante la tercera semana de inicio de síntomas. La sensibilidad de la prueba serológica rápida fue de $43,8 \%$ y la especificidad del 98,9\%. Conclusiones: La prueba serológica rápida logró detectar un mayor número de casos respecto a la molecular, sobre todo a partir de la segunda semana de inicio de síntomas. Además, presentó una alta especificidad. Los resultados mostrarían su utilidad como prueba complementaria a la prueba molecular, especialmente durante la segunda y tercera semana de enfermedad.

Palabras clave: Coronavirus; Estudios de Validación; Pruebas Serológicas; SARS-CoV-2; COVID-19 (fuente: DeCS BIREME).

\section{EVALUATION UNDER FIELD CONDITIONS OF A RAPID TEST FOR DETECTION OF IGM AND IGG ANTIBODIES AGAINST SARS-COV-2}

Citar como: Vidal-Anzardo M, Solis G Solari L, Minaya G, Ayala-Quintanilla B, Astete-Cornejo J, et al. Evaluación en condiciones de campo de una prueba rápida para detección de anticuerpos IgM e IgG contra SARS-CoV-2. Rev Peru Med Exp Salud Publica. 2020;37(2):203-9. doi: https://doi. org/10.17843/rpmesp.2020.372.5534

Correspondencia: Margot Haydée Vidal Anzardo; Cápac Yupanqui 1400, Jesús María, Lima, Perú; mvidal@ins.gob.pe

Recibido: $10 / 04 / 2020$ Aprobado: 20/04/2020

En línea: $22 / 04 / 2020$

\section{ABSTRACT}

Objective: To determine the additional diagnostic performance of a rapid serological test for detection of IgM and IgG antibodies compared to the real-time polymerase chain reaction (RT-PCR) test; for detection of SARS-CoV-2. Materials and methods: A cross-sectional study was carried out including patients hospitalized for COVID-19 in 3 hospitals, health workers exposed to the infection and outpatients who met suspicious case criteria, all of which underwent the molecular test (RT-PCR) and the rapid serological test. The additional diagnostic performance of rapid serological test was evaluated in comparison to molecular tests. Likewise, an approximation was made to the sensitivity and specificity of the rapid serological test. Results: 144 people were included. With the rapid test, $19.4 \%$ of positive results were obtained compared to $11.1 \%$ in the molecular test $(\mathrm{p}=0.03)$. The rapid serological test detected 21 cases that had been negative by the initial (RT-PCR), providing an additional diagnostic performance of $56.8 \%$ compared to the RT-PCR. The additional diagnostic performance was 50.0\% during the first week, $70.0 \%$ during the second week and $50.0 \%$ during the third week of symptom onset. The sensitivity of the rapid serological test was $43.8 \%$ and the specificity of $98.9 \%$. Conclusions: The rapid serological test was able to detect a greater number of cases than those detected by the molecular test especially after the second week of onset of symptoms. It also showed high specificity. It is therefore useful as a complementary test to RT-PCR, especially during the second and third week of illness.

Keywords: Coronavirus; Validation Studies; Serologic Test; SARS-CoV-2; COVID-19 (source: MeSH NLM). 


\section{INTRODUCCIÓN}

Al 7 de abril de 2020, la Organización Mundial de la Salud (OMS) reportó en las Américas un total de 417416 casos confirmados de infección por el virus SARS-CoV-2 (COVID-19) y 12597 fallecidos, de estos 2954 infectados y 107 muertos correspondían a Perú ${ }^{(1)}$.

El diagnóstico de infección por el virus SARS-CoV-2 se realiza mediante la prueba de reacción en cadena de la polimerasa con transcriptasa reversa en tiempo real (RT-PCR), la cual detecta la presencia del ARN viral. Esta prueba molecular (RT-PCR) es útil en las tres primeras semanas de infección y es actualmente el estándar de referencia recomendado por la OMS ${ }^{(2)}$. Sin embargo, la prueba tiene algunos inconvenientes como: alto costo; dificultad para implementarse en escenarios de recursos limitados; sensibilidad variable dependiendo del tipo de muestra (93\% en el lavado broncoalveolar, $72 \%$ en esputo, $63 \%$ en hisopado nasal y $32 \%$ en hisopado faríngeo) ${ }^{(3)}$; y su baja sensibilidad a partir de la tercera semana de iniciados los síntomas ${ }^{(4)}$.

Las pruebas inmunológicas pueden ser una ayuda diagnóstica complementaria y un apoyo importante en la vigilancia epidemiológica. Estas pruebas se basan en la detección de las inmunoglobulinas IgM e IgG contra SARS-CoV-2, las cuales aparecen a partir de la segunda semana de infección ${ }^{(5)}$. Existen pruebas basadas en la detección de anticuerpos en sangre venosa y sangre capilar. Estas últimas denominadas «pruebas serológicas rápidas», que permiten obtener resultados en pocos minutos. Sin embargo, la sensibilidad parece ser dependiente del momento de toma de muestra y puede ser mayor al $90 \%$ a partir de la segunda semana de síntomas ${ }^{(6)}$. Su uso podría contribuir de manera significativa al diagnóstico clínico, particularmente en pacientes hospitalizados, en quienes las pruebas moleculares hayan resultado negativas o no se hayan realizado ${ }^{(6)}$.

En el Perú, hasta fines de marzo del 2020, el diagnóstico de COVID-19 solo se realizó a través de las pruebas moleculares (aproximadamente 800 pruebas diarias). En un escenario de incremento del número de casos, se podría generar un subregistro. En dicho contexto, el gobierno peruano adquirió más de un millón de pruebas serológicas rápidas. Sin embargo, antes de su aplicación a gran escala era necesario evaluar su utilidad comparándolas con la prueba molecular.

El objetivo del estudio fue evaluar en condiciones de campo la prueba serológica rápida para detección de anticuerpos IgM e IgG, a través del cálculo de su rendimiento diagnóstico adicional en comparación al RT-PCR para la detección de infección por SARS-CoV-2.

\section{MATERIALES Y MÉTODOS}

\section{Participantes, tamaño muestral y muestreo}

Se realizó una investigación operativa de diseño transversal mediante el cual se incluyó tres tipos de sujetos: a) pacientes hospitalizados, con diagnóstico clínico y radiológico de neu-

\section{MENSAJES CLAVE}

Motivación para realizar el estudio: En el Perú, el diagnóstico de COVID-19 se basa en la prueba de reacción en cadena de la polimerasa con transcriptasa reversa en tiempo real (RT-PCR); sin embargo, las «pruebas serológicas rápidas» pueden ser un apoyo al diagnóstico, tomando en cuenta la sencillez de su aplicación y que el resultado se obtiene en diez minutos. Sin embargo, se requiere evaluar el rendimiento de dichas pruebas en condiciones de campo.

Principales hallazgos: Las pruebas serológicas rápidas dan un rendimiento diagnóstico adicional de 56,8\% en comparación con la prueba molecular y su sensibilidad aumenta con el tiempo de enfermedad.

Implicancias: Las pruebas serológicas rápidas son útiles como pruebas complementarias a la RT-PCR en el diagnóstico de COVID-19, su utilidad aumenta con el tiempo de enfermedad.

monía viral compatible con COVID-19 del Hospital Nacional Hipólito Unanue, Hospital Nacional Cayetano Heredia y Hospital Nacional Dos de Mayo; b) trabajadores de salud en permanente exposición a personas con diagnóstico confirmado de COVID-19 que se hubieran sometido a la prueba molecular en días previos al estudio; y c) personas que cumplían criterios de caso sospechoso según el Centro Nacional de Epidemiología, Prevención y Control de Enfermedades del Perú (persona sintomática con contacto directo con un caso confirmado de COVID-19 dentro de los 14 días previos al inicio de síntomas), evaluadas en sus casas por los equipos de alerta y respuesta.

Para evaluar la posibilidad de falsos positivos en otras condiciones febriles agudas, se realizó la prueba serológica rápida en 90 muestras de sueros almacenados en la seroteca de Biomedicina del Instituto Nacional de Salud (INS) de pacientes con diagnóstico confirmado de chikungunya, dengue, leptospira y zika (15 de cada una), de brucella, HBAsAg (+), hepatitis C (+), HIV(+), Oropuche (cinco de cada una), hipertrigliceridemia $(n=3)$ e hipercolesterolemia $(n=2)$, que hubieran brindado consentimiento para el uso de sus sueros en contexto de investigación.

En el grupo de casos sospechosos se pudo obtener muestras simultáneas para la evaluación de la prueba molecular y serológica rápida. En los pacientes hospitalizados y trabajadores de salud que ya contaban con toma de muestra de hisopado nasofaríngeo en días previos a la toma de pruebas serológicas rápidas, no fue posible un remuestreo por aspectos éticos.

Se calculó el tamaño de muestra, mediante la fórmula para una proporción en una población infinita considerando un nivel de confianza del $95 \%$ y un rendimiento diagnóstico adicional del 50\% (el estimado más conservador cuando no 
se conoce una proporción) de la serología con respecto al RT-PCR. Se consideró una precisión del 10\%. La muestra requerida fue de 97 pacientes. Asumiendo un $10 \%$ de pérdidas o datos incompletos el tamaño final fue de 108. El cálculo fue realizado utilizando el software libre OpenEpi (http://www. openepi.com/SampleSize/SSPropor.htm). El tipo de muestreo empleado fue no probabilístico por conveniencia.

\section{Procedimiento de RT-PCR}

El procesamiento de las muestras mediante RT-PCR se realizó siguiendo las recomendaciones de la Organización Panamericana de la Salud ${ }^{(2)}$, que permite detectar dos genes: al gen $\mathrm{E}$ (cuya presencia indica que pertenece a la familia de beta coronavirus) y RdRp (cuya presencia es específica para el SARS-CoV-2 y sirve como confirmación). Asimismo, se utilizó el gen RnaseP como control de inhibición. La prueba de RT-PCR fue realizada en muestras de hisopado nasal y faríngeo recolectadas mediante técnica estándar en medio de cultivo viral y transportadas al Laboratorio Nacional de Virus Respiratorios (LNVR) del INS en cadena de frío.

\section{Procedimiento de prueba serológica rápida}

La identificación de inmunoglobulinas IgG e IgM, se realizó de acuerdo a las recomendaciones del fabricante (COVID -19 IgG/IgM Rapid Test Cassette (wholeblood/serum/Plasma. Zhejang Orient Gene, Biotech Co LTD, China) ${ }^{(7)}$. La lectura requiere solo 10 minutos y que previamente se observe una primera banda (control) que indica que la prueba está bien realizada. La prueba serológica rápida se realizó mediante la obtención de sangre capilar por digito-punción de acuerdo a técnica estándar ${ }^{(8)}$.

\section{Análisis estadístico}

El análisis de los datos se llevó a cabo con el programa estadístico Stata v15.1 (Stata Corporation, College Station, Texas, USA) con el cual se caracterizó la conformación de la muestra por grupo evaluado aplicando la prueba Chi Cuadrado de Pearson para identificar diferencias entre sexo. Se utilizó la prueba T de Student para muestras independientes (con y sin varianzas iguales) y U de Mann-Whitney para identificar diferencias en las medidas descriptivas de la edad entre hombres y mujeres por grupo de estudio. Dichos cálculos se realizaron para la muestra total, así como para los pacientes con registro de tiempo de enfermedad.

Se obtuvo el porcentaje de pruebas positivas por cada uno de los métodos. El rendimiento diagnóstico adicional se calculó dividiendo el número de casos adicionales diagnosticados por las pruebas rápidas sobre el número total de casos detectados por ambos métodos, expresado en porcentaje ${ }^{(9)}$. Además, se realizó la estimación de la sensibilidad de la prueba serológica rápida usando el RT-PCR como estándar de referencia. Para la estimación de la especificidad se evaluó el porcentaje de pruebas serológicas negativas con respecto al total de muestras obtenidas a partir de las muestras de suero con positividad a otros patógenos. Todas los estimadores puntuales obtenidos fueron acompañados por su intervalo de confianza al 95\% (IC 95\%).

\section{Aspectos éticos}

En el contexto de la emergencia, el estudio ha sido aprobado bajo el procedimiento de «Revisión de protocolos en el marco de epidemias, brotes o situaciones de emergencia» por el Comité de Ética del Instituto Nacional de Salud, como lo señala la RD N¹12-2020-OGITT-INS.

\section{RESULTADOS}

La evaluación se realizó del 30 al 31 de marzo del 2020. De las 144 personas incluidas en el estudio hubo un dato faltante sobre el sexo. La distribución por grupo evaluado mostró diferencias estadísticamente significativas entre hombres y mujeres ( $\mathrm{n}=143$ ) (Tabla 1).

Para la evaluación de la edad se contó con información de 139 pacientes debido a la existencia de cinco datos faltantes en casos sospechosos, la edad promedio fue de 41,2 \pm 13,5 años, el grupo con mayor edad fue el de pacientes hospitalizados, seguido de los casos sospechosos y finalmente los trabajadores de salud. En la muestral total, no se encontró diferencias estadísticamente significativas para la edad entre hombres y mujeres ( $\mathrm{p}>0,05)$ (Tabla 2$)$.

En el grupo de personas evaluadas $(n=144)$, la prueba serológica rápida identificó $28(19,4 \%)$ sujetos positivos, y la prueba molecular $16(11,1 \%)(\mathrm{p}=0,03)$. La prueba serológica

Tabla 1. Características demográficas de la muestra de estudio.

\begin{tabular}{|c|c|c|c|c|}
\hline Grupo de estudio & $\begin{array}{c}\text { Femenino } \\
\text { n (\%) }\end{array}$ & $\begin{array}{c}\text { Masculino } \\
\text { n (\%) }\end{array}$ & $\begin{array}{c}\text { Total } \\
\mathbf{n}\end{array}$ & Valor de $\mathrm{p}^{\mathrm{b}}$ \\
\hline \multicolumn{5}{|l|}{ Muestra total } \\
\hline Pacientes hospitalizados & $6(25,0)$ & $18(75,0)$ & 24 & 0,005 \\
\hline Trabajadores de salud & $14(53,9)$ & $12(46,1)$ & 26 & \\
\hline Casos sospechosos ${ }^{a}$ & $58(62,4)$ & $35(37,6)$ & 93 & \\
\hline Total & $78(54,6)$ & $65(45,5)$ & 143 & \\
\hline
\end{tabular}

${ }^{a}$ Hubo un dato faltante por ausencia de información recolectada por las brigadas.

b Prueba Chi Cuadrado de Pearson. 
Tabla 2. Distribución de la edad en la muestra de estudio según sexo y grupo evaluado.

\begin{tabular}{|c|c|c|c|c|c|c|c|c|c|c|}
\hline \multirow[b]{2}{*}{ Grupo de estudio } & \multicolumn{3}{|c|}{ Total } & \multicolumn{3}{|c|}{ Femenino } & \multicolumn{3}{|c|}{ Masculino } & \multirow{2}{*}{$\begin{array}{l}\text { Valor } \\
\text { de p }\end{array}$} \\
\hline & $\mathbf{n}$ & $\begin{array}{c}\text { Media } \\
\text { (DE) }\end{array}$ & $\begin{array}{c}\text { Mediana } \\
\text { (RIQ) }\end{array}$ & $\mathbf{n}$ & $\begin{array}{c}\text { Media } \\
\text { (DE) }\end{array}$ & $\begin{array}{l}\text { Mediana } \\
\text { (RIQ) }\end{array}$ & $\mathbf{n}$ & $\begin{array}{c}\text { Media } \\
\text { (DE) }\end{array}$ & $\begin{array}{l}\text { Mediana } \\
\text { (RIQ) }\end{array}$ & \\
\hline \multicolumn{11}{|l|}{ Muestra total } \\
\hline $\begin{array}{l}\text { Pacientes } \\
\text { hospitalizados }\end{array}$ & 24 & $48,5(13,1)$ & $\begin{array}{c}44,5 \\
(41,0-59,0)\end{array}$ & 6 & $45,7(21,2)$ & $\begin{array}{c}38,0 \\
(28,0-66,0)\end{array}$ & 18 & $49,5(9,7)$ & $\begin{array}{c}47,0 \\
(41,0-56,0)\end{array}$ & $0,684^{\mathrm{b}}$ \\
\hline $\begin{array}{l}\text { Trabajadores de } \\
\text { salud }\end{array}$ & 26 & $38,4(9,0)$ & $\begin{array}{c}36,5 \\
(32,0-46,0)\end{array}$ & 14 & $37,9(9,3)$ & $\begin{array}{c}36,0 \\
(32,0-42,0)\end{array}$ & 12 & $39,1(9,1)$ & $\begin{array}{c}40,0 \\
(30.5-48,0)\end{array}$ & $0,738^{c}$ \\
\hline Casos sospechosos ${ }^{a}$ & 89 & $40,0(14,1)$ & $\begin{array}{c}36,0 \\
(29,0-47,0)\end{array}$ & 55 & $40,4(13,9)$ & $\begin{array}{c}36,0 \\
(29,0-47,0)\end{array}$ & 34 & $39,2(14,6)$ & $\begin{array}{c}35,0 \\
(28,0-49,0)\end{array}$ & $0,667^{\mathrm{d}}$ \\
\hline Total & 139 & $41,2(13,5)$ & $\begin{array}{c}39,0 \\
(31,0-49,0)\end{array}$ & 75 & $40,4(13,8)$ & $\begin{array}{c}36,0 \\
(29,0-46,0)\end{array}$ & 64 & $42,1(13,2)$ & $\begin{array}{c}42,0 \\
(31,5-50,0)\end{array}$ & $0,266^{\mathrm{d}}$ \\
\hline
\end{tabular}

${ }^{a}$ Hubo cinco datos faltantes por ausencia de información recolectada por las brigadas.

${ }^{\mathrm{b}}$ Prueba $\mathrm{T}$ de Student para muestras independientes con varianzas diferentes.

${ }^{c}$ Prueba T de Student para muestras independientes con varianzas iguales.

d Prueba U de Mann-Whitney.

DE: Desviación estándar, RIQ: Rango Intercuartil.

rápida detectó 21 casos que habían resultado negativos por la molecular, dando un rendimiento diagnóstico adicional de 56,8\%. En estos 21 casos, 13 fueron pacientes hospitalizados con criterio clínico y radiológico de neumonía viral compatible con COVID-19 y ocho fueron casos sospechosos con más de siete días de enfermedad (excepto uno que no tenía dato), ambos grupos con factores de riesgo (Tabla 3).

\section{Evaluación por tiempo de enfermedad}

De los 144 sujetos incluidos, se identificó que 109 presentaban información de la fecha de inicio de síntomas $(75,7 \%)$, con ello se estableció el tiempo promedio de enfermedad hasta el día de la evaluación diagnóstica (17,59 $\pm 4,1$ días). Para los sujetos que días previos ya habían brindado mues-

Tabla 3. Resultados de la prueba serológica en comparación con el RT-PCR según tiempo de enfermedad.

\begin{tabular}{lccc}
\hline & \multicolumn{2}{c}{ RT-PCR } & Total \\
\cline { 2 - 3 } Tiempo de enfermedad & $\begin{array}{c}\text { Positivo } \\
\mathbf{n}(\%)\end{array}$ & $\begin{array}{c}\text { Negativo } \\
\mathbf{n}(\%)\end{array}$ & $\mathbf{n}(\%)$ \\
\hline $\begin{array}{l}\text { Primera semana } \\
\quad \text { Positivo }\end{array}$ & $0(0,0)$ & $2(7,7)$ & $2(7,1)$ \\
$\quad$ Negativo & $2(100)$ & $24(92,3)$ & $26(92,9)$ \\
$\quad$ Total & $2(100)$ & $26(100)$ & $28(100)$ \\
Segunda semana & & & \\
$\quad$ Positivo & $2(33,3)$ & $14(25,9)$ & $16(26,7)$ \\
$\quad$ Negativo & $4(66,7)$ & $40(74,1)$ & $44(73,3)$ \\
$\quad$ Total & $6(100)$ & $54(100)$ & $60(100)$ \\
Después de segunda semana & & & \\
$\quad$ Positivo & $2(50,0)$ & $4(23,5)$ & $6(28,6)$ \\
$\quad$ Negativo & $2(50,0)$ & $13(76,5)$ & $15(71,4)$ \\
$\quad$ Total & $4(100)$ & $17(100)$ & $21(100)$ \\
\hline
\end{tabular}

RT-PCR: Prueba de reacción en cadena de la polimerasa con transcriptasa reversa en tiempo real. tras para la prueba molecular, se consideró como fecha de evaluación el día de la evaluación por prueba serológica rápida; con estos valores se categorizó el periodo de enfermedad según semana de manifestación clínica, identificándose que $60(55,1 \%)$ cursaban la segunda semana de enfermedad, $28(25,7 \%)$ la primera y $21(19,3 \%)$ más de dos semanas (Tabla 3). La Figura 1 muestra las pruebas positivas mediante ambas pruebas de acuerdo al día de inicio de síntomas.

Durante la primera semana de síntomas, el rendimiento diagnóstico adicional de la prueba serológica rápida fue de $50 \%$ con respecto al RT-PCR. En la segunda semana, fue de $70 \%$ y luego de la segunda semana, el rendimiento diagnóstico adicional fue de $50 \%$ con respecto al RT-PCR (Tabla 3 , Figura 2).

\section{Evaluación por grupo de estudio}

En los 94 pacientes evaluados de manera domiciliaria el rendimiento diagnóstico adicional fue de $50 \%$ con respecto al RT-PCR; en los 24 pacientes hospitalizados, el rendimiento diagnóstico adicional fue $65 \%$ (Tabla 4, Figura 2).

\section{Sensibilidad}

Al comparar los resultados de la prueba rápida con los resultados de la molecular, la prueba rápida mostró un $43,8 \%$ de sensibilidad (IC 95\%: 19,8 - 70,1). Según semana de enfermedad, se encontró que la sensibilidad aumentaba gradualmente con el tiempo, identificándose $0 \%$ durante la primera semana, 33,3\% en la segunda y 50,0\% para después de la segunda semana. Según grupo evaluado, se encontró una mayor sensibilidad en pacientes hospitalizados (71,4\%; IC 95\% 29,0-96,3), seguido de los casos sospechosos (25,0\%; IC 95\%: 3,19-65,1) (Tabla 5).

\section{Especificidad}

Se realizaron pruebas rápidas en 90 muestras de sueros de pacientes con infecciones por diferentes patógenos, de las 


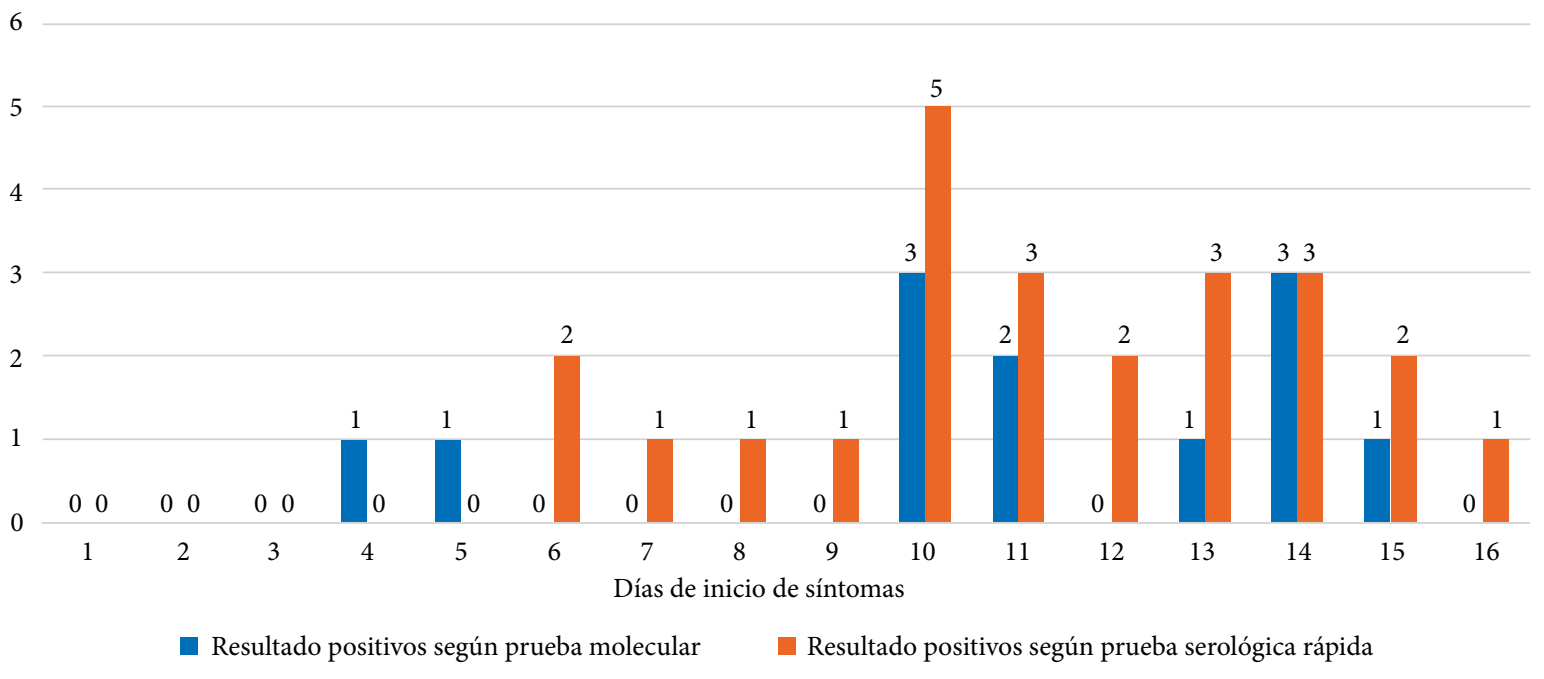

Figura 1. Distribución de resultados positivos obtenidos por día según prueba utilizada.

cuales solo una resultó positiva en un paciente con infección por VIH correspondiendo a una especificidad del 98,9 (IC 95\%: 94,0-100).

\section{DISCUSIÓN}

Al comparar el rendimiento de la prueba molecular y de la prueba rápida, observamos que esta última identificó $56,8 \%$ casos adicionales. En la estratificación por grupo de estudio, la prueba rápida detectó $61,9 \%$ y $38,1 \%$ casos adicionales en pacientes hospitalizados y casos sospechosos visitados en el

Tabla 4. Resultados de la prueba serológica en comparación con el RT-PCR según grupo de estudio.

\begin{tabular}{|c|c|c|c|}
\hline \multirow[b]{2}{*}{ Grupo de estudio } & \multicolumn{2}{|c|}{ RT-PCR } & \multirow{2}{*}{$\begin{array}{l}\text { Total } \\
\text { n (\%) }\end{array}$} \\
\hline & $\begin{array}{c}\text { Positivo } \\
\text { n (\%) }\end{array}$ & $\begin{array}{c}\text { Negativo } \\
\text { n (\%) }\end{array}$ & \\
\hline \multicolumn{4}{|c|}{ Pacientes hospitalizados } \\
\hline Positivo & $5(71,4)$ & $13(76,5)$ & $18(75,0)$ \\
\hline Negativo & $2(28,6)$ & $4(23,5)$ & $6(25,0)$ \\
\hline Total & $7(100)$ & $17(100)$ & $24(100)$ \\
\hline \multicolumn{4}{|c|}{ Trabajadores de salud } \\
\hline Positivo & $0(0,00)$ & $0(0,0)$ & $0(0,0)$ \\
\hline Negativo & $1(100)$ & $25(100)$ & $26(100)$ \\
\hline Total & $1(100)$ & $25(100)$ & $26(100)$ \\
\hline \multicolumn{4}{|l|}{ Casos sospechosos } \\
\hline Positivo & $2(25,0)$ & $8(9,3)$ & $10(10,6)$ \\
\hline Negativo & $6(75,0)$ & $78(90,7)$ & $84(89,4)$ \\
\hline Total & $8(10)$ & $86(100)$ & $94(100)$ \\
\hline \multicolumn{4}{|l|}{ Sueros } \\
\hline Positivo & $0(0,0)$ & $1(1,1)$ & $1(1,1)$ \\
\hline Negativo & $0(0,0)$ & $89(98,9)$ & $89(98,9)$ \\
\hline Total & $0(0,0)$ & $90(100)$ & $90(100)$ \\
\hline
\end{tabular}

RT-PCR: Prueba de reacción en cadena de la polimerasa con transcriptasa reversa en tiempo real domicilio, respectivamente. De igual manera, cuando tomamos en cuenta el tiempo de enfermedad, observamos que se incrementa la cantidad de casos positivos conforme aumenta dicho tiempo.

El rendimiento diagnóstico de la prueba rápida fue superior a la prueba molecular a partir de la segunda semana de síntomas. Esto concuerda con lo reportado por Xie et al. ${ }^{(10)}$ quien encontró que la prueba rápida identificó cinco casos positivos que habían tenido un RT-PCR inicial negativo en pacientes hospitalizados con neumonía clínica y radiológicamente compatible con COVID-19 y con contactos positivos, y que finalmente tuvieron un RT-PCR positivo después de múltiples muestras. Asimismo, es similar o lo reportado por Zhao y Gao, quienes observan que la presencia de anticuerpos aumenta conforme aumenta el tiempo de enfermedad, de $18,8 \%$ a $53,8 \%$ en la primera semana a $87,5 \%$ a $89,6 \%$ en la segunda semana. Según Liu la presencia de anticuerpos es de $91,3 \%$ a $100 \%$ después de los 15 días de enfermedad ${ }^{(4,6,10,11)}$.

La prueba molecular puede resultar negativa en una persona infectada con el SARS-CoV-2 cuando: a) la extracción de la muestra, manejo, transporte o almacenamiento de la misma no fue realizada de manera adecuada; b) existe presencia de inhibidores del RT-PCR en la muestra de ARN extraídos; y c) cuando la cantidad de virus es insuficiente para ser detectada, lo cual ocurre en etapas muy tempranas o muy tardías de la infección. La carga viral es diferente dependiendo del estadio de la infección, de manera que cuando el sistema inmune produce los anticuerpos, el virus disminuye pudiendo no ser detectable por la prueba molecular ${ }^{(2,12)}$.

La evaluación de la especificidad se realizó con 90 muestras de una colección de sueros obtenidos antes del inicio de la epidemia de COVID-19 en China, por lo que fueron consideradas como referencias negativas. $\mathrm{Al}$ aplicar la prueba rápida en estos sueros, solo se obtuvo un resultado positivo 


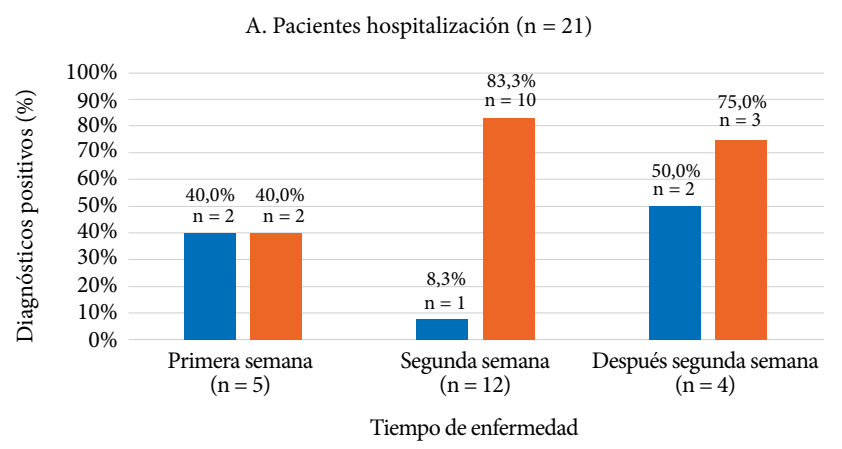

Positivo según prueba molecular — Positivo según prueba serológica rápida

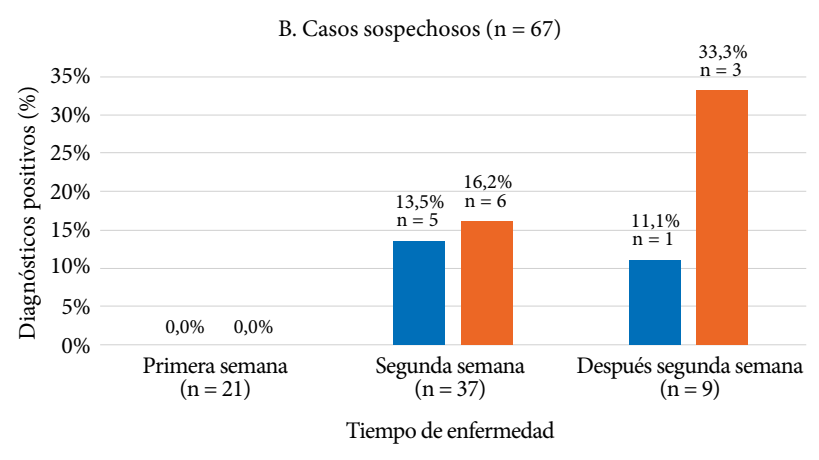

Positivo según prueba molecular — Positivo según prueba serológica rápida

Figura 2. Distribución de resultados positivos obtenidos por grupo evaluado y tiempo de enfermedad según prueba utilizada.

en un paciente con infección por VIH, resultando una especificidad de $98,9 \%$. Esta forma de evaluación también fue realizada por Zang et al. quien realizó la prueba rápida en un grupo de pacientes con otras enfermedades diferentes a COVID-19 y encontró 99,1\% de especificidad ${ }^{(13)}$.

Los resultados sugieren que ambas pruebas son complementarias por su capacidad diagnóstica en función del tiempo de infección. Si se tiene un resultado positivo mediante cualquiera de las dos metodologías el diagnóstico está definido. Estos hallazgos son consistentes con lo encontrado por Gao Yaung et al. el cual reporta que en los siete primeros días la sensibilidad del RT-PCR era de 69,2\%, disminuye a 25,0\% a la segunda semana, y llega a $13,0 \%$ para después de la segunda semana, encontrando en contraparte un rendimiento diagnóstico ascendente de la prueba serológica ${ }^{(4)}$.

Tabla 5. Sensibilidad de la prueba serológica rápida en comparación con el RT-PCR como prueba de referencia

\begin{tabular}{|c|c|c|c|c|}
\hline \multirow{2}{*}{ Grupo de estudio } & \multicolumn{2}{|c|}{ Prevalencia } & \multicolumn{2}{|c|}{ Sensibilidad } \\
\hline & $\mathbf{n}$ & $\%($ IC $95 \%)$ & $\mathbf{n}$ & $\%$ (IC 95\%) \\
\hline Muestra total $(\mathrm{n}=234)^{\mathrm{a}}$ & 16 & $\begin{array}{c}6,8 \\
(4,0-10,9)\end{array}$ & 7 & $\begin{array}{c}43,8 \\
(19,8-70,1)\end{array}$ \\
\hline Pacientes hospitalizados & 7 & $\begin{array}{c}29,2 \\
(13,0-51,1)\end{array}$ & 5 & $\begin{array}{c}71,4 \\
(29,0-96,3)\end{array}$ \\
\hline Trabajadores de salud & 1 & $3,8^{\mathrm{b}}$ & 0 & $0,0^{\mathrm{b}}$ \\
\hline Casos sospechosos & 8 & $\begin{array}{c}8,5 \\
(3,7-16,1)\end{array}$ & 2 & $\begin{array}{c}25,0 \\
(3,2-65,1)\end{array}$ \\
\hline $\begin{array}{l}\text { Muestra con información } \\
\text { sobre tiempo de enfermedad } \\
(n=109)\end{array}$ & 12 & $\begin{array}{c}11,0 \\
(5,8-18,4)\end{array}$ & 4 & $\begin{array}{c}33,3 \\
(9,9-65,1)\end{array}$ \\
\hline Primera semana & 2 & $\begin{array}{c}7,1 \\
(0,9-23,5)\end{array}$ & 0 & $\begin{array}{c}0,0 \\
(0,0-84,2)\end{array}$ \\
\hline Segunda semana & 6 & $\begin{array}{c}10,0 \\
(3,8-20,5)\end{array}$ & 2 & $\begin{array}{c}33,3 \\
(4,3-77,7)\end{array}$ \\
\hline $\begin{array}{l}\text { Después de segunda } \\
\text { semana }\end{array}$ & 4 & $\begin{array}{c}19,0 \\
(5,4-41,9)\end{array}$ & 2 & $\begin{array}{c}50,0 \\
(6,8-93,2)\end{array}$ \\
\hline
\end{tabular}

${ }^{a}$ Considera a sujetos con y sin dato de tiempo de enfermedad.

${ }^{b}$ No se pudo calcular estimador ni intervalo de confianza por escasa cantidad de casos.

IC 95\% = Intervalo de Confianza al 95\%, RT-PCR: Prueba de reacción en cadena de la polimerasa con transcriptasa reversa en tiempo real.
Dentro de las limitaciones se encuentra el reducido tamaño muestral, si bien nos permitió evaluar el rendimiento diagnóstico adicional de la prueba rápida fue insuficiente para llegar a conclusiones en los subgrupos específicos, y por ende, tenemos intervalos de confianza muy amplios en las estimaciones e incluso en algunos casos no pudieron ser calculados. Adicionalmente, debemos señalar que nuestros estimados de sensibilidad y especificidad representan datos preliminares y que deben corroborarse en estudios de mayor tamaño muestral.

Otro factor importante es la falta de información clínica, incluso algunos pacientes no tenían información sobre el número de días de síntomas. Por otra parte, al considerar que la prueba rápida daba un diagnóstico adicional al haber identificado casos positivos que no habían sido identificados por la prueba molecular inicial, estamos asumiendo que los casos adicionales identificados por la prueba rápida corresponden a pacientes realmente infectados. Este supuesto se basa, en que los pacientes hospitalizados y ambulatorios que cumplían la definición de casos, tenían criterios clínicos y radiológicos de neumonía sugerente de infección por COVID-19.

Idealmente, se debería realizar un seguimiento longitudinal de estos pacientes para evaluar el momento en que tanto la prueba molecular como la rápida se vuelve o dejan de ser positivos. Otro factor importante es el poco número de positivos entre los trabajadores de salud, lo cual impide asumir conclusiones en este grupo en particular. Por último, no hemos ahondado en las diferencias entre las bandas IgM e IgG, puesto que, en esta evaluación, solo tres pacientes tuvieron bandas IgG aisladas, todos los otros positivos tuvieron ambas bandas. En el futuro y con más pruebas rápidas realizadas se podrá establecer la importancia de la diferencia entre estas bandas ${ }^{(12)}$.

Por otro lado, esta evaluación constituye un primer abordaje a la utilidad de las pruebas rápidas para diagnóstico de infección por SARS-CoV-2. En medio de controversias mediáticas y a pesar de la falta de recomendaciones para su uso 
por parte de agencias internacionales, nuestros resultados aportan evidencia científica a favor de su uso en condiciones de campo, con la finalidad de fortalecer el diagnóstico tanto de pacientes hospitalizados como en casos sospechosos ambulatorios. Dicha aplicación sería relevante en la contención comunitaria de la epidemia al identificar zonas afectadas de novo, así como en el registro de casos severos y muertes.

En conclusión, las pruebas serológicas rápidas brindan un rendimiento diagnóstico adicional a las pruebas moleculares de manera particular a partir de la segunda semana del inicio de síntomas y en pacientes hospitalizados. En el contexto de la actual epidemia es recomendable su uso como prueba complementaria a la molecular, especialmente a partir de la segunda semana. Se recomienda realizar estudios en muestras mayores, y poder valorar adecuadamente el rendimiento diagnóstico de ambas pruebas en subgrupos específicos.

Contribución de los autores: MV, GS y LS han participado en la concepción y diseño del artículo. MV, GS, GM, BA, JA y AL participaron en la recolección de los datos. NR, FC y AJ participaron en el procesamiento de las muestras, MV, GS, LS y AS participaron en el análisis estadístico de datos. Todos los autores participaron en la interpretación de los datos, redacción del manuscrito, revisión crítica del manuscrito, aprobaron la versión final y se hacen responsables del contenido del artículo.

\section{REFERENCIAS BIBLIOGRÁFICAS}

1. Pan American Health Organization. Cumulative COVID-19 cases reported by countries and territories [Internet]. Washington DC: PAHO/WHO; 2020 [citado 8 abril 2020]. Disponible en: https:// who.maps.arcgis.com/apps/webappviewer/index.html?id=2203 b04c3a5f486685a15482a0d97a87\&extent $=-17277700.8881 \% 2 \mathrm{C}$ 1043174.5225\%2C-1770156.5897\%2C6979655.9663\%2C10210.

2. Pan American World Health Organization. Laboratory Guidelines for the Detection and Diagnosis of COVID-19 Virus Infection [Internet]. Washington DC: PAHO/WHO; 2020 [citado 8 abril 2020]. Disponible en: https://www.paho.org/En/Documents/Laboratory-GuidelinesDetection-And-Diagnosis-Covid-19-Virus-Infection.

3. Wang W, Xu Y, Gao R, Lu R, Han K, Wu G, et al. Detection ofSARS-CoV-2 in Different Types of Clinical Specimens. JAMA. Published online March 11, 2020. doi: 10.1001/jama.2020.3786 [Epub ahead of print].

4. Gao Y, Yuan Y, Li TT, Wang WX, Li YX, Li A, et al. Evaluation the auxiliary diagnosis value of antibodies assays for detection of novel coronavirus (SARS-Cov-2) causing an outbreak of pneumonia (COVID-19). medRxiv [Internet]. 2020 Jan 1 [citado el 1 de marzo de 2020]. Disponible en: https://www.medrxiv.org/content/10.1101/2020.03.26.20042044v1. full.pdf doi: 10.1101/2020.03.26.20042044.

5. Swee Saw Hock School of Public Health. Research on COVID-19 [Internet]. Singapore: SSHSPH COVID-19 Science Reports. 2020 [citado el 1 de marzo de 2020]. Disponible en: https://sph.nus.edu.sg/covid-19/ research/.

6. Zhao J, Yuan Q, Wang H, Liu W, Liao X, Su Y, et al. Antibody responses to SARS-CoV-2 in patients of novel coronavirus disease 2019. Clin Infect Dis. 2020 Mar 28. pii: ciaa344. doi: 10.1093/cid/ciaa344. [Epub ahead of print].
Fuentes de financiamiento: La investigación fue financiada a través del Centro Nacional de Salud Pública del Instituto Nacional de Salud de Perú.

Conflictos de interés: Todos los autores a excepción de Alonso Soto son trabajadores del Instituto Nacional de Salud. Margot Vidal Anzardo es Directora Ejecutiva de la Dirección Ejecutiva de Enfermedades No Transmisibles/Centro Nacional de Salud Pública. Lely Solari es Directora General del Centro Nacional de Salud Pública y miembro del Comité Editor de la Revista Peruana de Medicina Experimental y Salud Pública. Jonh Astete Cornejo es Director Ejecutivo de la Dirección de Medicina y Psicología del Trabajo/Centro Nacional de Salud Ocupacional y Protección del Medio Ambiente para la Salud. Ana Jorge es Coordinadora del Laboratorio de Referencia Nacional de Bacterias de Transmisión Sexual. Nancy Rojas es Coordinadora de Laboratorio de Virus Respiratorios. Fanny Cardenas es Coordinadora del Laboratorio de Virus de Transmisión Sexual y VIH/SIDA. Alonso Soto es miembro del Comité Editor de la Revista Peruana de Medicina Experimental y Salud Pública.

Agradecimientos: Al equipo de brigadistas del INS dirigidos por Ana Zeppilli, por tomar las pruebas rápidas en el grupo de casos sospechosos a través de los equipos de Alerta y Respuesta. A todo el personal del Laboratorio de Referencia Nacional de Virus Respiratorio del Centro Nacional de Salud Pública del Instituto Nacional de Salud, por su dedicada labor en el procesamiento de las muestras para la prueba molecular. A las autoridades y personal de salud que nos permitieron realizar el estudio en el Hospital Nacional Cayetano Heredia, Hospital Nacional Hipólito Unanue y en el Hospital Nacional Dos de Mayo.
7. Healgen ${ }^{\circ}$ COVID-19 [Internet]. Zhejiang Orient Gene Biotech Co.,LTD; 2020 [citado 8 abril 2020]. Disponible en: http://www.orientgene.com/ asp-en/product/ list.aspx?category_id=1094\&product_id=8398.

8. Instituto Nacional de Salud. Prueba Rápida de coronavirus COVID-19 [Internet]. Lima: INS; 2020 [citado 8 abril 2020]. Disponible en: https:// web.ins.gob.pe/es/pr.

9. Soto A, Acurio V, Solari L, Der Stuyft P Van. Incremental yield of bronchial washing for diagnosing smear-negative pulmonary tuberculosis. Rev Saude Publica. 2013;47(4):813-6. doi: 10.1590/S0034-8910.2013047004548.

10. Xie X, Zhong Z, Zhao W, Zheng C, Wang F, Liu J. Chest CT for typical 2019- nCoV Pneumonia Relationship to negativa RT-PCR testing. Radiology. 2020. doi: 10.1148/radiol.2020200343.

11. Liu Y, Liu Y, Diao B, Ren F, Wang Y, Ding J, et al. Diagnostic Indexes of a Rapid IgG/IgM Combined Antibody Test for SARS-CoV-2. medRxiv [Internet]. 2020 Jan 1 [citado el 1 de marzo de 2020]. Disponible en: https://www.medrxiv.org/content/10.1101/2020.03.26.20044883v1. full.pdf doi: 10.1101/2020.03.26.20044883.

12. Li Z, Yi Y, Luo X, Xiong N, Liu Y, Li S, et al. Development and Clinical Application of A Rapid IgM-IgG Combined Antibody Test for SARSCoV-2 Infection Diagnosis. J Med Virol [Internet]. 2020; [citado el 1 de marzo de 2020]. Disponible en: https://www.ncbi.nlm.nih.gov/ pubmed/32104917 doi: 10.1002/jmv.25727.

13. Zhang J, Liu J, Li N, Liu Y, Ye R, Qin X, et al. Serological detection of 2019$\mathrm{nCoV}$ respond to the epidemic: A useful complement to nucleic acid testing. medRxiv [Internet]. 2020 Jan 1 [citado el 1 de marzo de 2020]; Disponible en: https://www.medrxiv.org/content/10.1101/2020.03.04.20030916v2.full. pdf doi: 10.1101/2020.03.04.20030916. 